\title{
Políticas públicas de educação inclusiva no Brasil e na Bahia: avanços e recuos
}

\author{
Public policies for inclusive education in Brazill and Bahia: advances and returns \\ Políticas públicas para la educación inclusiva en Brasil y Bahia: avances y devoluciones
}

Recebido: 15/02/2021 | Revisado: 21/02/2021 | Aceito: 25/02/2021 | Publicado: 04/03/2021

Luciana Canário Mendes

ORCID: https://orcid.org/0000-0003-1239-3692

Universidade de Pernambuco, Brasil

E-mail: luciana.canariomendes@upe.br

Deyse Almeida dos Reis

ORCID: https://orcid.org/0000-0002-6627-1247

Instituto Federal de Educação, Ciência e Tecnologia de Minas Gerais, Brasil

E-mail: deysereis.reis@gmail.com

\begin{abstract}
Resumo
Este artigo tem como objetivo analisar a trajetória das políticas educacionais da educação especial/inclusiva no Brasil, bem como apontar as perspectivas desta modalidade de ensino no Estado da Bahia. Para isso, adotamos como procedimentos metodológicos a pesquisa qualitativa, de caráter bibliográfico e documental. No que concerne a revisão bibliográfica recorremos aos estudos de Jannuzzi \& Caiado (2013), Mazzota (1996), Mantoan (2002), Cruz \& Monteiro (2019), Oliveira \& Glat (2003), dentre outros; dentre as fontes documentais, utilizamos a Declaração de Salamanca e algumas legislações educacionais, como a Leis de Diretrizes e Bases da Educação Nacional, $n^{\circ}$ 4.024/1961 e n ${ }^{\circ}$ 9394/1996 e, em âmbito regional, as Diretrizes da Educação Inclusiva para pessoas com Deficiências, Transtornos Globais do Desenvolvimento e Altas Habilidades/Superdotação (2017), documento elaborado pelo Estado da Bahia. Pela observação dos aspectos analisados, destacamos a necessidade de uma ação conjunta de todos os segmentos da sociedade no intuito de minimizar a distância entre os dispositivos legais e o cotidiano escolar.
\end{abstract}

Palavras-chave: Educação inclusiva; Educação especial; Políticas educacionais.

\begin{abstract}
This article aims to analyze the trajectory of educational policies for special / inclusive education in Brazil, as well as to point out the perspectives of this type of teaching in the State of Bahia. For this, we adopted bibliographic and documentary research as methodological procedures. Regarding the bibliographic review, we used the studies of Jannuzzi \& Caiado (2013), Mazzota (1996), Mantoan (2002), Cruz \& Monteiro (2019), Oliveira \& Glat (2003), among others; Among the documentary sources, we use the Salamanca Declaration and some educational legislation, such as the National Education Guidelines and Bases Laws, No. 4024/1961 and No. 9394/1996 and, at the regional level, the Inclusive Education Guidelines for People with Disabilities, Global Development Disorders and High Skills / Giftedness (2017), a document prepared by the State of Bahia. By observing the aspects analyzed, we highlight the need for joint action by all segments of society in order to minimize the distance between legal provisions and school life.
\end{abstract}

Keywords: Inclusive education; Special education; Educational policies.

\section{Resumen}

Este artículo tiene como objetivo analizar la trayectoria de las políticas educativas para la educación especial / inclusiva en Brasil, así como señalar las perspectivas de este tipo de enseñanza en el Estado de Bahía. Para ello, adoptamos la investigación bibliográfica y documental como procedimientos metodológicos. En cuanto a la revisión bibliográfica, se utilizaron los estudios de Jannuzzi \& Caiado (2013), Mazzota (1996), Mantoan (2002), Cruz \& Monteiro (2019), Oliveira \& Glat (2003), entre otros; Entre las fuentes documentales, utilizamos la Declaración de Salamanca y alguna legislación educativa, como las Directrices y Bases Leyes Nacionales de Educación, No 4024/1961 y No 9394/1996 y, a nivel regional, las Directrices de Educación Inclusiva para Personas con Discapacidad, Trastornos del Desarrollo Global y High Skills / Giftedness (2017), documento elaborado por el Estado de Bahía. Al observar los aspectos analizados, destacamos la necesidad de una acción conjunta de todos los segmentos de la sociedad para minimizar la distancia entre las disposiciones legales y la vida escolar.

Palabras clave: Educación integrada; Educación especial; Políticas educativas. 


\section{Introdução}

Esta pesquisa deriva de uma inquietação ocorrida durante o Curso de Especialização em Educação Básica, com ênfase em Educação Inclusiva, realizada no Instituto Federal de Minas Gerais (IFMG). As discussões realizadas nas disciplinas nos motivaram a investigar a trajetória histórica das políticas educacionais, bem como a situação da educação baiana frente a este cenário.

É imprescindível destacar que, compreendemos como política educacional as medidas, iniciativas e ações do Estado no campo da educação, representadas pelas leis, pelo planejamento, pelo financiamento e pelos programas educacionais. Então, é "o Estado em ação" imprimindo os rumos da educação nacional (Azevedo, 2004).

Assim, exploramos inicialmente a trajetória da educação especial/inclusiva, neste interim, analisamos as legislações e documentos emblemáticos, a exemplo da Declaração de Salamanca, que inaugura o conceito de educação inclusiva. No âmbito nacional, nos debruçamos na Constituição Federal de 1988, nas Leis de Diretrizes e Bases da Educação Nacional (LDB), ${ }^{\circ}$ 4.024/61 e no 9394/1996, dentre outras; e no âmbito regional, focamos especialmente nas Resoluções $\mathrm{n}^{\circ} 04$ e $\mathrm{n}^{\circ}$ 79/2009 e Diretrizes da Educação Inclusiva para pessoas com Deficiências, Transtornos Globais do Desenvolvimento e Altas Habilidades/Superdotação (2017), documento elaborado pelo Estado da Bahia.

\section{Metodologia}

Como procedimento metodológico utilizamos a pesquisa qualitativa, caracterizada pela importante interpretação do pesquisador sobre o fenômeno em estudo (Pereira et al., 2018, p. 67), de natureza bibliográfica (constituída principalmente de livros e artigos científicos e documental (que tem como suporte "os materiais que não receberam um tratamento analítico, ou que ainda podem ser reelaborados de acordo com os objetos da pesquisa" (Gil, 2008)). Utilizamos fontes primárias e secundárias e tentamos refletir considerando os momentos históricos de suas elaborações legais.

Em vista disso, realizamos uma revisão bibliográfica de autores que investigam as políticas educacionais voltadas para a educação especial/inclusiva, a saber Jannuzzi \& Caiado (2013), Mazzotta (1996), Cruz (2002), Mantoan (2002), dentre outros; bem como recorremos a fontes documentais como as legislações referentes à temática em questão, com destaque para as Diretrizes da Educação Inclusiva para pessoas com Deficiências, Transtornos Globais do Desenvolvimento e Altas Habilidades/Superdotação (2017), documento elaborado pelo Estado da Bahia.

\section{Resultados e Discussão}

\subsection{História da Educação Especial no Brasil: breves referências}

Mazzota (1996) assegura que, a escolarização da educação especial brasileira foi inspirada na Europa e na América do Norte. Segundo este autor, havia uma combinação de práticas assistencialistas e uma parcela significativa da população contava com o apoio de instituições privadas e filantrópicas.

No Brasil Colônia, as crianças com deficiência eram abandonadas nas Santas Casas de Misericórdia e, também, pelas confrarias particulares, como a Irmandade de Santa Ana, na cidade de Vila Rica (Souza, 1991). Posteriormente, por ordem do imperador Pedro II, foram criados o Imperial Instituto dos Meninos Cegos (1854), hoje conhecido como, Instituto Benjamim Constant, e o Instituto dos Surdos-Mudos (1856). No entanto, segundo dados oficiais, tivemos entre o Brasil Colônia e a Primeira República: Brasil Colônia (1500-18220): 02 instituições; Brasil Império (1822-1889): 5 instituições; Brasil Primeira República (1889-1930): 24 instituições (Brasil, 1975). No entanto, em 1872, existiam 15.848 cegos e 11.595 surdos no país e, apenas 35 cegos e 17 surdos eram atendidos nestas instituições (Mazzotta, 1996, p.29). 
Na Primeira República, especificadamente em 1934, foi implantada a Sociedade Pestalozzi, organizada pela educadora Helena Antipoff. Entre os anos de 1934 a 1950 foram organizadas 07 instituições da Sociedade Pestalozzi, dentre os 52 estabelecimentos de ensino especial existentes no Brasil (Jannuzi \& Caiado, 2013). Segundo estas autoras, em 1954 foi criada a primeira Associação de Pais e Amigos dos Excepcionais (APAE) ${ }^{1}$.

Importante registrar que, a Constituição Federal de 1946 estabeleceu a obrigatoriedade de criação, em cada sistema de ensino, de serviços que assegurassem aos alunos necessitados condições de eficiência escolar.

O autor divide a trajetória da educação especial no Brasil em três grandes períodos, sendo o primeiro, compreendido entre os anos de 1954 a 1956, marcado por iniciativas isoladas.

Mazzotta (1996) define os anos de 1957 a 1993 como a segunda fase, marcada por um avanço nas iniciativas públicas, especialmente em relação a campanhas e estruturação de órgãos voltados para as pessoas com deficiência.

Nesse período, foi promulgada a primeira Lei de Diretrizes e Bases da Educação Nacional (LDB), nº 4.024/1961, dentre outras medicas, garantiu o direito à educação para o público "excepcional": "Art. 88. A educação de excepcionais, deve, no que fôr possível, enquadrar-se no sistema geral de educação, a fim de integrá-los na comunidade” (Brasil, 1961)2.

Na Bahia, nos anos finais da década de 1950 e nos anos 1960, apesar da inconstância nos serviços da educação especial, foram realizadas várias iniciativas de inserção de alunos com deficiência visual (1959) nas escolas Getúlio Vargas³, Marquês de Abrantes ${ }^{4}$ e no Instituto Central de Educação Isaías Alves, oferecendo atendimento especializado no Instituto de Cegos, no turno oposto ao turno em que essas crianças estavam matriculadas (Cruz, 2002, p. 22).

Dez anos depois da LDB, foi promulgada a Lei $n^{\circ} 5.692 / 1971$ que determinou:

Art. $9^{\circ}$ Os alunos que apresentem deficiências físicas ou mentais, os que se encontrem em atraso considerável quanto à idade regular de matrícula e os superdotados deverão receber tratamento especial, de acôrdo com as normas fixadas pelos competentes Conselhos de Educação (Brasil, 1971).

Por meio do Decreto $\mathrm{n}^{\circ} 72.425$, de 1973, o governo federal instituiu o Centro Nacional de Educação Especial (CENESP) com a intenção de promover a qualificação e ampliação do atendimento dos "excepcionais".

Na Bahia, em 1975 foi instituído um Conselho para organizar oficialmente o serviço educacional especializado, efetivado com o Decreto 24.618 e a Resolução 224, apresentando a seguinte estrutura: a) Grupo de Educação Especial de Deficientes da Audição e da Fala - GEDAF; b) Grupo de Educação Especial de Deficientes da Visão - GEDAV; c) Grupo de Educação Especial de Deficientes da Motricidade - GEDAM; d) Grupo Pestalozzi - ou de Educação Especial dos Deficientes Mentais (BAHIA, 1976, p. 14).

Em 1978, pela Emenda Constitucional n ${ }^{\circ}$ 12, que inaugura a garantia da educação especial: "É assegurado aos deficientes a melhoria de sua condição social e econômica, especialmente mediante: I - Educação especial e gratuita.

Os movimentos de participação social e legislações contribuíram para a elaboração da Constituição Federal de 1988 que prescreveu que a educação é um direito fundamental. Para tanto, os sistemas de ensino devem organizar-se no sentido de garantir a igualdade, o acesso e a permanência de todos na escola. Em seu art. $3^{\circ}$, IV, elenca como objetivos fundamentais, a promoção do bem comum a todos, sem preconceitos de raça, sexo, cor, idade e quaisquer outras formas de discriminação.

Ao estabelecer tais objetivos, o texto constitucional aponta as diretrizes de como deve se desenvolver a política de educação inclusiva no país, levando em consideração o direito à igualdade, com vistas ao desenvolvimento pleno e à garantia

\footnotetext{
${ }^{1}$ Entre 1954 a 1974 foram implantadas 198 instituições em 16 estados (Jannuzi \& Caiado, 2013).

${ }^{2}$ Segundo Jannuzzi \& Caiado (2013, p. 9), o nome "excepcional” foi introduzido entre nós pela educadora Helena Antipoff, em substituição aos anteriormente usados: "idiotas", "retardados", "imbecis",

${ }^{3}$ Foi nessa instituição que a SEC criou a primeira classe especial da Bahia, abrindo também na Escola Barão de Macaúbas, com a oferta do serviço itinerante a outras unidades escolares (Bahia, 1976, p. 14).

4 "Nesta escola estadual, em 1961 foi criada a primeira sala de recursos da Bahia" (Cruz, 2002, p. 22).
} 
de que ao cidadão serão dadas todas as condições, no sentido de prepará-lo para o exercício da cidadania. E atribuiu ao Estado à tarefa de proporcionar Atendimento Educacional Especializado (AEE) aos "portadores de deficiência" (CF, art. 208, parágrafo III).

A última fase, para Mazzota (1996) se deu a partir de 1994, com a promulgação da Declaração de Salamanca (1994) que determinou como dever do Estado a formulação das políticas públicas de educação inclusiva para o atendimento e a permanência dos alunos em instituições escolares, independentemente de suas condições físicas, intelectuais, sociais, emocionais, linguísticas ou outras. Segundo o documento:

[...] o princípio fundamental da escola inclusiva é o de que todas as crianças deveriam aprender juntas, independentemente de quaisquer dificuldades ou diferenças que possam ter. As escolas inclusivas devem reconhecer e responder às diversas necessidades de seus alunos, acomodando tanto estilos como ritmos diferentes de aprendizagem e assegurando uma educação de qualidade a todos através de currículo apropriado, modificações organizacionais, estratégias de ensino, uso de recursos e parceiras com a comunidade [...] Dentro das escolas inclusivas, as crianças com necessidades educacionais especiais deveriam receber qualquer apoio extra que possam precisar, para que se lhes assegure uma educação efetiva (Declaração de Salamanca, 1994, p.5).

Estes deveriam ser os princípios a serem implantados pelos países signatários, na consolidação de uma educação de qualidade para todas as pessoas, principalmente para as que apresentam necessidades educativas especiais, num conceito de escola integradora. Mesmo representando uma demarcação político-social para garantir os direitos educacionais da pessoa com deficiência, o termo "Educação Inclusiva" não se materializou no corpo desse documento.

Sob a ótica de uma educação especial no contexto de um sistema educacional inclusivo, Mantoan (2002), apresenta a seguinte reflexão:

O que define o especial da educação não é a dicotomização e a fragmentação dos sistemas escolares em modalidades diferentes, mas a capacidade de a escola atender às diferenças nas salas de aula, sem discriminar, sem trabalhar à parte com alguns, sem estabelecer regras específicas para se planejar, para aprender, para avaliar (currículos, atividades, avaliação da aprendizagem).

O especial da educação tem a ver com a inclusão total, incondicional de todos os alunos às escolas de seu bairro, como cita Salamanca, e que ultrapassa o âmbito dos alunos com deficiência, englobando- -os, sem dúvida. Este especial da educação não é requerido apenas para a inserção de alunos com deficiência, mas para que possamos reverter uma situação vergonhosa da escola brasileira, hoje, marcada pelo fracasso e pela evasão de uma parte significativa dos seus alunos. Em outras palavras, este especial qualifica as escolas que são capazes de incluir os alunos excluídos, indistintamente, descentrando os problemas relativos à inserção total dos alunos com deficiência e focando o que realmente produz essa situação lamentável de nossas escolas. (...)

É certo que os alunos com deficiência constituem uma grande preocupação para os educadores inclusivos, mas todos sabemos que maioria dos alunos que fracassam na escola são crianças que não vêm do ensino especial, mas que possivelmente acabarão nele! (...) Em uma palavra, mudam as escolas e não mais os alunos!

Por se tratar de um direito constitucional, o inciso I, do artigo 206, a Constituição estabeleceu a "igualdade de condições de acesso e permanência na escola" e, mais a frente garantia que, a oferta do AEE deverá ocorrer, preferencialmente, na rede regular de ensino (art. 208).

Pouco depois, foi promulgado o Estatuto da Criança e do Adolescente (ECA). Ambas as leis continuaram priorizando o atendimento do aluno com deficiência no ensino regular com a participação das instituições particulares.

\subsection{Educação Especial/Inclusiva: dispositivos legais}

Ancorada nos postulados da Constituição Federal de 1988 e das conferências mundiais, especialmente da Declaração de Salamanca, foi promulgada no Brasil a LDB, n 9.394/1996. Esta, determinou a adequação das escolas brasileiras para atender satisfatoriamente a todas as crianças. Diferenças étnicas, sociais, culturais ou de qualquer ordem passam a ser foco do 
discurso de inclusão escolar. Em vista disso, a Lei que destinou o capítulo cinco "Da Educação Especial" e a definiu como uma modalidade de educação escolar, para educandos com deficiência, transtornos globais do desenvolvimento e altas habilidades ou superdotação, a ser ofertada preferencialmente, na rede regular de ensino.

$\mathrm{O}$ artigo subsequente assegurou que, quando necessário, haverá serviços de apoio especializado, na escola regular e que tal atendimento acontecerá em função das condições específicas dos alunos com currículos, métodos, técnicas e recursos educativos para atender as diferentes necessidades. Garantiu ainda aos professores uma especialidade adequada para o atendimento especializado, dentre outras.

O Art. 60 estabeleceu que o Poder Público adotará, como alternativa preferencial, a ampliação do atendimento na própria rede pública regular de ensino, independentemente do apoio às instituições. Portanto, vislumbra-se que o serviço de apoio especializado parece ter um caráter facultativo, já que a lei deixa claro que sua oferta se dará quando necessária. Verifica-se assim que, no texto da referida lei, não há uma uniformidade quanto aos termos utilizados para definir o atendimento a ser oferecido ao aluno. Tais termos aparecem de quatro maneiras diferentes: "atendimento educacional especializado", "atendimento especializado", "serviços de apoio especializado" e "serviços especializados", contudo parecem definir o mesmo tipo de serviço.

Na Bahia, na perspectiva da educação inclusiva, dois anos após a aprovação da LDB, foi oficializada a implantação, em Salvador (1998) do primeiro Centro de Apoio Pedagógico para Atendimento às Pessoas com Deficiência Visual (CAP), objetivando atender à crescente demanda dos alunos cegos, inseridos nas escolas regulares, ampliando em seguida para as demais Unidades Federadas do país (CRUZ, 2002, p. 23).

No âmbito nacional, a Lei no 10.436/02 reconheceu a Língua Brasileira de Sinais como meio legal de comunicação e expressão, bem como a inclusão da disciplina de Libras como parte integrante do currículo nos cursos de formação de professores e de fonoaudiologia.

Em 2002, por meio da Portaria n $2.678 / 02$, o Ministério da Educação (MEC) aprovou as diretrizes e normas para o uso, o ensino, a produção e a difusão do Sistema Braille em todas as modalidades de ensino, compreendendo o projeto da Grafia Braile para a Língua Portuguesa e a recomendação para o seu uso em todo o território nacional.

O Decreto $\mathrm{n}^{\circ}$ 5.626/05, visando à inclusão dos alunos surdos, dispôs sobre a inserção de Libras como disciplina curricular, a formação e a certificação de professor, instrutor e tradutor/intérprete de Libras, o ensino da língua portuguesa como segunda língua para alunos surdos e a organização da educação bilíngue no ensino regular.

Em relação aos recursos financeiros, o Plano de Desenvolvimento da Educação (PDE), de 2007, trouxe como eixos a acessibilidade arquitetônica dos prédios escolares, a implantação de salas de recursos multifuncionais e a formação docente para o AEE.

Ao assumir os princípios da inclusão como marco político, ideológico, social, cultural e pedagógico na Política Nacional de Educação Especial na Perspectiva da Educação Inclusiva (MEC/2008), o Brasil estabeleceu um compromisso na busca de caminhos para garantir o direito de todos à educação. Tal documento conceituou a Educação Inclusiva como: [...] um paradigma educacional fundamentado na concepção de direitos humanos, que conjuga igualdade e diferença como valores indissociáveis, e que avança em relação à idéia de eqüidade formal ao contextualizar as circunstâncias históricas da produção da exclusão dentro e fora da escola (Brasil, 2008, p. 5).

Como afirmação dos preceitos da Educação Inclusiva, a Bahia, através do seu Conselho de Educação, estabeleceu normas com este propósito dispostas na Resolução nº 79/2009, definindo, no seu Art. $1^{\circ}$, a Educação Especial e o seu públicoalvo, voltada para os estudantes com deficiência de natureza motora, intelectual ou sensorial, transtornos globais do desenvolvimento e altas habilidades/superdotação (Art. $5^{\circ}$, incisos I, II e III). 
O governo baiano lançou o programa Rede de Educação Especial: um caminho para a inclusão, estabelecendo uma parceria entre os Institutos de Educação Superior (IES) e as Organizações Não-Governamentais (ONGs). Um dos pilares desse Programa foi a formação de professores para a atuação com o público da Educação Especial. Outras ações surgiram no desenvolvimento dessa proposta, como, por exemplo, a criação de 05 centros de apoio pedagógico especializado no interior ${ }^{5}$, com a intenção de ampliar e fortalecer a Educação Inclusiva (Diretrizes, ...)

Em 2009, a Resolução n. ${ }^{\circ} 4$ instituiu as Diretrizes Operacionais para o Atendimento Educacional Especializado na Educação Básica, modalidade Educação Especial, e estabeleceu as formas possíveis desse atendimento:

Art. $1^{\circ}$ Para a implementação do Decreto $\mathrm{n}^{\circ}$ 6.571/2008, os sistemas de ensino devem matricular os alunos com deficiência, transtornos globais do desenvolvimento e altas habilidades/superdotação nas classes comuns do ensino regular e no Atendimento Educacional Especializado (AEE), ofertado em salas de recursos multifuncionais ou em centros de Atendimento Educacional Especializado da rede pública ou de instituições comunitárias, confessionais ou filantrópicas sem fins lucrativos (Brasil, 2009).

Pela Portaria $n^{\circ}$ 2344/2010, os sujeitos até então chamados de "portadores" de necessidades educativas especiais recebera uma nova identificação: pessoas com deficiência (Brasil, 2010).

$\mathrm{Na}$ perspectiva da acessibilidade, em 2011, foi aprovado o decreto $\mathrm{n}^{\circ} 7.611$ que dispõe sobre o atendimento educacional especializado. Na lei é dever do Estado essa modalidade de educação, o público-alvo da educação especial previsto na LDB, e define que AEE (conjunto de atividades, recursos de acessibilidade e pedagógicos organizados institucional e continuamente), garantir as condições para a continuidade de estudos nos demais níveis, etapas e modalidades de ensino.

O decreto determinou que é dever do Estado com a educação das pessoas público-alvo da educação especial será efetivado de acordo com as seguintes diretrizes:

[...] I - garantia de um sistema educacional inclusivo em todos os níveis, sem discriminação e com base na igualdade de oportunidades;

II - aprendizado ao longo de toda a vida;

III - não exclusão do sistema educacional geral sob alegação de deficiência;

IV - garantia de ensino fundamental gratuito e compulsório, asseguradas adaptações razoáveis de acordo com as necessidades individuais - oferta de apoio necessário, no âmbito do sistema educacional geral, com vistas a facilitar sua efetiva educação;

VI - adoção de medidas de apoio individualizadas e efetivas, em ambientes que maximizem o desenvolvimento acadêmico e social, de acordo com a meta de inclusão plena;

VII - oferta de educação especial preferencialmente na rede regular de ensino;

VIII - apoio técnico e financeiro pelo Poder Público às instituições privadas sem fins lucrativos, especializadas e com atuação exclusiva em educação especial (Brasil, 2011, s/p).

Verificamos que, como reflexo dessa diretriz inclusiva da política educacional um crescimento significativo de matrículas na educação especial nas classes comuns da escola regular nos últimos anos, conforme gráfico a seguir:

${ }^{5}$ Nos municípios de Caetité, Ipiaú, Itabuna, Jequié e Santo Antônio de Jesus. 
Gráfico 1 - Percentual de matrículas de alunos de 4 a 17 anos de idade com deficiência, transtornos globais do desenvolvimento e altas habilidades ou superdotação em classes comuns da educação básica -2007-2018

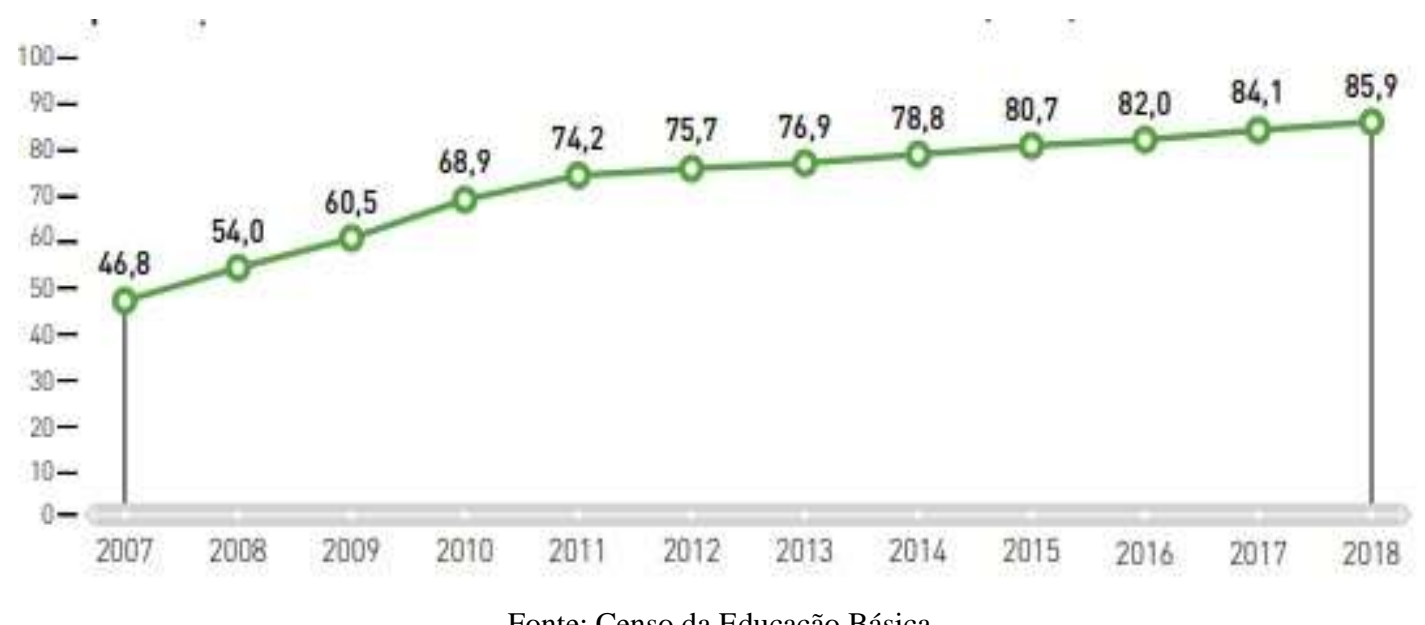

Fonte: Censo da Educação Básica.

Conforme apresentado no gráfico, é evidente que a inclusão vem sendo ampliada em classes comuns no Brasil. A taxa passou de 46,8\%, em 2007, para 85,9\%, em 2018. Cruz \& Monteiro (2019) asseguram que, o crescimento foi de 17,4 pontos percentuais na Educação Infantil, 10,9 pontos percentuais no Ensino Fundamental e, 23,4 pontos percentuais no Ensino Médio. Contudo, segundo os autores:

[...] faltam informações que permitam avançar na compreensão desse quadro. Os dados são relativos apenas a quem está na escola, via Censo Escolar. Não há estatísticas satisfatórias sobre as crianças e jovens pertencentes a esse grupo que não possuem acesso à Educação, pois o Censo Demográfico, além de ser decenal, ainda precisa aprimorar a forma de apuração e de coleta das informações sobre essa população (Cruz \& Monteiro, 2019, p. 46).

Importante também destacar as Leis n $12.764 / 2012$, que instituiu a Política Nacional de Proteção dos Direitos da Pessoa com Transtorno do Espectro Autista e a Lei no 13.005/2014 institui o Plano Nacional de Educação (PNE), que sugeriu

Meta 4: universalizar, para a população de quatro a dezessete anos com deficiência, transtornos globais do desenvolvimento e altas habilidades ou superdotação, o acesso à educação básica e ao atendimento educacional especializado, preferencialmente na rede regular de ensino, com a garantia de sistema educacional inclusivo, de salas de recursos multifuncionais, classes, escolas ou serviços especializados, públicos ou conveniados (Brasil, 2014).

Dispositivos legais mais recentes, como a Lei $n^{\circ}$ 13.146, Lei Brasileira de Inclusão da Pessoa com Deficiência (Estatuto da Pessoa com Deficiência), sancionada em 2016 destina-se a assegurar e a promover, em condições de igualdade, o exercício dos direitos e das liberdades fundamentais por pessoa com deficiência, visando à sua inclusão social e cidadania. Deste documento, consideramos importante destacar o conceito de pessoa com deficiência:

[...] aquela que tem impedimento de longo prazo de natureza física, mental, intelectual ou sensorial, o qual, em interação com uma ou mais barreiras, pode obstruir sua participação plena e efetiva na sociedade em igualdade de condições com as demais pessoas (Brasil, 2016).

Visando atender a tais demandas, o Estado da Bahia aprovou, em 2017, as Diretrizes da Educação Inclusiva para pessoas com Deficiências, Transtornos Globais do Desenvolvimento e Altas Habilidades/Superdotação. Este documento constitui um marco orientador, norteando a prática pedagógica dos professores da rede estadual e organizando as estruturas da Secretaria da Educação no que tange à inclusão do público-alvo da Educação Especial. 
Segundo o documento, a rede estadual conta com Atendimento Educacional Especializado (AEE), que hoje está disponível para mais de oito mil estudantes com necessidades educacionais especiais. São 65 Salas de Recursos Multifuncionais (SRM), 12 Centros de Atendimento Educacional Especializado e seis instituições conveniadas. Os alunos são atendidos nas escolas da rede e nos Centros de Educação Especial, dentro de suas especificidades, para que possam participar ativamente do ensino regular.

Apesar do incremento no número de matriculados na educação especial na educação especial nas classes comuns da escola regular nos últimos anos, percebemos uma carência de informações relativas aos sujeitos que não tem acesso à educação formal. Assim, os documentos aqui mencionados têm como ponto comum discursos que,

[...] que defendem práticas inclusivas no campo educacional como promotoras de inclusão social, numa perspectiva que não questiona o atual sistema social, ao contrário, propõem reparos sociais para aqueles que deles necessitam (...) Especificamente em relação aos alunos com deficiência, as práticas inclusivas são seguidamente relacionadas a serviços ou atendimento especializados (Garcia, 2015, p. 16).

Ao lado disso, surgem outros questionamentos, a exemplo da elaboração do projeto político-pedagógico e o currículo (englobando metodologias, avaliação e estratégias de ensino) devem incorporar ações que favoreçam a inclusão social e práticas educativas diferenciadas que atendam a todos os alunos (Oliveira \& Glat, 2003).

Complementarmente, Hernandez (2011) assegura que, para ocorrer a inclusão é necessário problematizar a cultura, as práticas docentes, o currículo escolar, o sistema educativo, ampliando a conscientização e formando para a diversidade. Para o autor supracitado, o processo da inclusão passa pela conscientização, tomada de atitude, ampliação de conhecimentos e capacitação docente.

No âmbito nacional, é importante destacar que, no ano passado foi sancionado o Decreto $\mathrm{n}^{\circ} 10.502$, que instituiu a Política Nacional de Educação Especial: Equitativa, Inclusiva e com Aprendizado ao Longo da Vida. Tal dispositivo determinou como público-alvo:

I - educandos com deficiência, conforme definido pela Lei no 13.146, de 6 de julho de 2015 - Estatuto da Pessoa com Deficiência;

II - educandos com transtornos globais do desenvolvimento, incluídos os educados com transtorno do espectro autista, conforme definido pela Lei $\mathrm{n}^{\mathrm{o}}$ 12.764, de 27 de dezembro de 2012; e

III - educandos com altas habilidades ou superdotação que apresentem desenvolvimento ou potencial elevado em qualquer área de domínio, isolada ou combinada, criatividade e envolvimento com as atividades escolares (Brasil, 2020).

Temos a convicção de que as políticas educacionais, mesmo sob semblante muitas vezes humanitário e benfeitor, expressam sempre as contradições. Na qualidade de processo social, construído historicamente, configura-se como "um complexo contraditório de condições históricas que implicam um movimento de ida e de volta entre as forças sociais em disputa", conforme destaca Cury (2001).

\section{Considerações Finais}

A filosofia de uma escola inclusiva é almejada por gestores, professores, alunos, famílias e a comunidade. Sabemos que isso só será possível a partir de políticas educacionais gradativas, contínuas e sistemáticas. Percebemos que os dispositivos legais referentes a educação numa perspectiva inclusiva requerem uma reorganização das estruturas das instituições escolares. Isso envolve o acesso e permanência na escola, a formação e qualificação dos professores, currículo, métodos, recursos, organizações e infraestrutura adequada, dentre outros. 
Infelizmente, a nossa experiência tem evidenciado que, ainda faltam em muitas escolas regulares salas de recursos multifuncionais (são ambientes dotados de equipamentos, mobiliários e materiais didáticos e pedagógicos para a oferta do AEE), assim como professores com conhecimentos específicos no ensino (de Libras, sistema Braille, Tecnologia Assistiva, entre outros) para que este serviço ocorra de maneira eficaz. Falta também estrutura física adequada, pois embora existam leis federais (Leis Federal no 10.098/2000 e a NBR no 9.050/2005) que definem os requisitos para acessibilidade, o que temos, de forma geral, são edifícios escolares que ainda não se adequaram as essas exigências legais.

Ficou evidente para nós a interferência de alguns organismos financeiros, mormente o Banco Mundial e Fundo Monetário Internacional (FMI) na elaboração das políticas educacionais brasileiras, uma vez que compreendemos que, em se tratando de políticas educacional, o global e o local se interpenetram e se contaminam, mesmo que em condições de desigualdade.

\section{Referências}

Azevedo, J. M. L. de. (2004). A Educação Como Política Pública. Polêmicas do nosso tempo. Campinas: Autores Associados.

Bareta, E. M.\& Canan, S. R. (2012). Políticas Públicas de Educação Inclusiva: avanços e recuos a partir dos documentos legais. Anais do IX ANPED-SUL.

Brasil (1994). Declaração de Salamanca e linha de ação sobre necessidades educativas especiais. Brasília: CORDE.

Brasil (1996). Lei $n^{\circ}$ 9.394, de 20 de dezembro de 1996. Estabelece as diretrizes e bases da educação nacional.

Brasil (2001). Decreto $n^{o}$ 3.956, de 8 de outubro de 2001. Promulga a Convenção Interamericana para a Eliminação de Todas as Formas de Discriminação contra as Pessoas Portadoras de Deficiência.

Brasil (2007). Decreto Presidencial n. 6.094, de 24 de abril de 2007. Dispõe sobre a implementação do Plano de Metas Compromisso Todos pela Educação, pela União, em regime de colaboração com municípios, Distrito Federal e Estados.

Brasil (2008). Política Nacional de Educação Especial na Perspectiva da Educação Inclusiva. Brasília: MEC/SEESP.

Brasil (2009). Decreto $n^{\circ}$ 6.949, de 25 de agosto de 2009. Promulga a Convenção Internacional sobre os Direitos das Pessoas com Deficiência e seu Protocolo Facultativo, assinados em Nova York, em 30 de março de 2007.

Brasil (2011). Decreto $n^{o}$ 7.611, de 17 de novembro de 2011. Dispõe sobre a educação especial, o atendimento educacional especializado e dá outras providências.

Brasil (2011). Decreto $n^{\circ}$ 7.616, de 17 de novembro de 2011. Dispõe sobre a declaração de Emergência em Saúde Pública de Importância Nacional - ESPIN e institui a Força Nacional do Sistema Único de Saúde - FN-SUS.

Brasil (2011). Secretaria de Educação Especial. Diretrizes Nacionais para a Educação Especial na Educação Básica. Brasília: MEC/SEESP.

Brasil (2014). Lei no 13.005, de 25 de junho de 2014. Aprova o Plano Nacional de Educação (PNE) e dá outras providências.

Brasil (2015) Lei n ${ }^{o}$ 13.146, de 6 de julho de 2015. Institui a Lei Brasileira de Inclusão da Pessoa com Deficiência (Estatuto da Pessoa com Deficiência).

Cruz, C. M. P. (2002). Integração escolar do aluno com cegueira: da intenção à ação. 2002. 182f. Dissertação (Mestrado em Educação Especial) Universidade Estadual de Feira de Santana. UEFS, Feira de Santana.

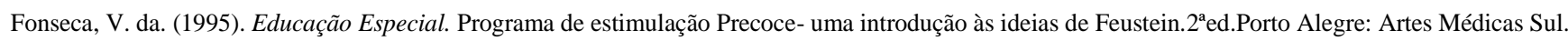

Garcia, R. M C. (2015). Políticas inclusivas na educação: do global e o local. In: Baptista, C. R. (org.). Educação especial: diálogo e pluralidade. 3. Ed. Porto Alegre: Mediação.

Gil, A. C. (2008). Como elaborar projetos de pesquisa. (4a ed.), Atlas.

Jannuzzi, G. de M. \& Caiado, K R. M. (2013). APAE: 1954 a 2011 algumas reflexões. Campinas, SP: Autores Associados - (Coleção polêmicas do nosso tempo).

Mantoan, M. T. E. (2002). A educação especial no Brasil: da exclusão à inclusão escolar. Campinas: Leped/Unicamp.

Mazzota, M. J. S. (1996). Educação especial no Brasil: história e políticas públicas. Cortez. 
Research, Society and Development, v. 10, n. 3, e5110312989, 2021

(CC BY 4.0) | ISSN 2525-3409 | DOI: http://dx.doi.org/10.33448/rsd-v10i3.12989

Oliveira, E. da S. G. \& Glat, R. (2003). Educação Inclusiva: ensino fundamental para os portadores de necessidades especiais. In: Valle, B. de B. R. (et. al). Fundamentos teóricos e metodológicos do ensino fundamental. Curitiba: IESDE.

Pereira, A. S. et.al. (2018). Metodologia da pesquisa científica. UFSM. 